\title{
Depression, possibilities, and competence: A phenomenological perspective
}

\author{
Gerben Meynen
}

Published online: 6 January 2011

(C) The Author(s) 2011. This article is published with open access at Springerlink.com

\begin{abstract}
Competent decision-making is required for informed consent. In this paper, I aim, from a phenomenological perspective, to identify the specific facets of competent decision-making that may form a challenge to depressed patients. On a phenomenological account, mood and emotions are crucial to the way in which human beings encounter the world. More precisely, mood is intimately related to the options and future possibilities we perceive in the world around us. I examine how possibilities should be understood in this context, and how, in depression, decision-making might be compromised. I suggest that, based on this analysis, a specific emphasis and alertness in assessments of competence in depressed patients is called for. In fact, close attention should be paid to the range of future possibilities depressed patients are able to perceive. In addition, providing environmental cues to these patients might be one way of enhancing their decision-making capacity. The practical suggestions arrived at are open to empirical research.
\end{abstract}

Keywords Depression · Mood · Competence · Decision-making · Possibilities · Phenomenology

\section{Introduction}

As a general principle, doctors are required to obtain the informed consent of their patients before beginning treatment. Valid informed consent is only obtainable after the appropriate information has been disclosed to a competent patient [1-3]. Generally, four abilities are deemed necessary for (competent) decision-making:

G. Meynen $(\bowtie)$

Faculty of Philosophy and EMGO Institute, VU University Amsterdam, De Boelelaan 1105, 1081 HV Amsterdam, The Netherlands e-mail: g.meynen@ph.vu.nl 
firstly, the ability to express a choice; secondly, the ability to understand the relevant information; thirdly, the ability to appreciate one's situation and the consequences of the options; and finally, the ability to reason about treatment choices [3, 4]. The MacCAT-T was developed as an assessment tool based on these four domains relevant to competent decision-making [5]. The four domains and the MacCAT-T have been considered suitable for identifying those who are incompetent due to cognitive impairments, like various forms of dementia $[6,7]$. However, there are doubts about whether this approach to competence is equally helpful for evaluating competence in patients suffering from other mental disorders.

One of these disorders is major depression. Abraham Rudnick argues that while major depression may not impair the four abilities generally considered necessary for competence, it may 'disrupt coherence of personal preferences by changing them' [8]. According to Rudnick, such a change may be assessed by comparing the patient's preferences during the depressive episode to his treatment preferences during periods without depression. If current preferences are not consistent with earlier treatment preferences in 'normal' periods then there is ground for treating the patient as incompetent. In a paper on competence to consent to research, Carl Elliott argued that it may well be that (severely) depressed patients are incompetent to consent to research because, first, it may be unclear whether their decisions are authentically theirs, and second, some of these patients may not have sufficient concern for their own well-being [9]. Elliott, then, argues that assessments of competence must take emotional factors into account. This suggestion is also put forward by Louis Charland [7, 10] with respect to competence assessments in general (see the 'Implications' section below; see also [11]). End of life decisions is one specific area in which the issue of competence in depression is considered relevant [12].

The reported percentage of depressed patients who are actually considered not to be competent with respect to treatment decisions varies. Depending on the type of assessment (either MacCAT or clinical assessment by the attending physician), Jochen Vollmann et al. found impaired competence in $2.9 \%$ (physician assessed) or $20.0 \%$ (MacCAT) of the patients with depression [13]. ${ }^{1}$ Furthermore, Gareth Owen et al. observed a 'striking' relationship between mood and decision-making capacity in psychiatric inpatients [15]. Depressed mood in nonpsychotic disorders turned out to be strongly associated with incapacity. On a conceptual level, the question is about how to conceive of the challenges faced by depressed patients when it comes to deciding between treatment options. The mere assertion that emotions play a role may not be sufficient from this conceptual viewpoint; rather, an understanding is needed about the nature of the link between emotions and the decision-making process.

In this article, I aim, from a phenomenological perspective, to identify the specific facets of competent decision-making that form a challenge to (severely) depressed patients. Following phenomenological accounts by, among others, Matthew Ratcliffe [16], Michael Wheeler [17], and Martin Heidegger [18], I argue

\footnotetext{
${ }^{1}$ See Young et al. [14] for four case studies on depression and competence.
} 
that in (severe) mood disorders, the actual appreciation of possibilities may change. ${ }^{2}$ This calls for a specific emphasis and alertness in assessments of competence in these patients. I also propose that phenomenological theorizing-especially Wheeler's account-suggests the means of supporting depressed patients when making treatment decisions.

The outline of the paper is as follows. In the next section, the phenomenological context of highlighting the topic of perceiving possibilities in people with mood disorders is discussed. Then, in the section following, I relate this analysis to the theoretical debate on competence. In the final section, possible implications of the analysis so far with respect to actual assessments of competence are explored.

\section{Phenomenology: Perceiving possibilities and mood}

\section{Perceiving possibilities}

From a phenomenological perspective, particularly drawing on a Heideggerian analysis, human existence is to be understood from the start as being-in-the-world [18]. This conceptual approach is meant to provide a different angle on human functioning than, for example, a Cartesian Ego (see [17, pp. 18-19]). It implies that human beings are, from the start, conceived of as being in interaction with the world. In fact, the world has already been implicated in our self-appreciation or selfawareness; there is no self without a world.

The interesting point is how this interaction is understood from a conceptual point of view. What is the way in which we relate to other worldly entities? What is the fabric of being-in-the-world made of? According to Ratcliffe, it is the concept of possibility. This concept is directly derived from Heidegger's early work [16]. Human agency $^{3}$ is approached, step by step, in terms of possibility, or beingpossible. The world as it surrounds us is not a world of objects that we encounter in some detached appreciation. Rather, when we engage the objects, we have already appreciated and perceived the possibilities provided by them. A famous example is the analysis of our relationship to a hammer [18, p. 98]. It is not the case that a person engages it as a 'thing' with a wooden component and an iron part, etc.; it is in fact something with which he can hammer. He perceives something that provides the possibility of 'hammering'. In our everyday engagement, we interpret the 'objects' primarily as making certain actions possible. When we are involved in the process of building, for instance, we pick up the materials that seem fit for the job

\footnotetext{
${ }^{2}$ In this article, I will not distinguish between mood and emotions. In Being and Time, Heidegger basically uses the term Stimmung (mood), yet he also uses the term Befindlichkeit which is hard to translate but clearly refers to the affective dimension of being-in-the-world (see also Ratcliffe [16, p. 308]). With respect to the distinction between mood and emotion, Ratcliffe writes, 'I treat moods as a specific sub-class of emotions. Heidegger's discussion focuses on moods. However, I will suggest in what follows that his theory can be generalized to encompass emotions more generally' [16, p. 308]. I agree with Ratcliffe that such a generalization is possible.

3 In technical terms, 'being-there' (Dasein). Wheeler uses the term 'human agency' and 'the human agent' [17, p. 122].
} 
without much thought. We continuously engage the world by perceiving such practice related possibilities. As Svenaeus puts it, 'The most basic access [to things in the word] ... relies on our handling the stuff of the world in various ways to attain things. The chair is not first and foremost an object with such-and-such a shape and colour; it is something to sit on, and we approach it in such a way when we take a seat or offer it to somebody else in inviting her for a cup of coffee. The world ... does not consist of objects but of "tools"...' [19, p. 182]. Notably, engaging the world is certainly not limited to objects or tools, but instead, reaches out to include the other people that we encounter. Recognizing the world, i.e., our surroundings, from this possibility-perspective is not something we can turn off. It is both natural and intrinsic to the way we are.

It is important to acknowledge two elements in the perception of possibilities. First, there is not just one possibility attached to a hammer. For instance, a hammer can be used to hammer. But the hammering itself is part of a broader scope of possibilities, namely to fix things and to build. And building, in turn, entails the possibility of constructing a house. Furthermore, constructing a house implies the possibility of shelter for a person (the builder himself). So, possibilities do not stop, but go on infinitely. Every possibility opens up a field of further possibilities. According to Wheeler, the human agent 'confronts every concrete situation in which she finds herself ... as a range of possibilities for acting...' [17, p. 122; emphasis added]. These possibilities, of course, are not always explicit, and we are not actively aware of all these possibilities [17]. We know that when we arrive in New York City there will be endless possibilities, but we surely are not consciously aware of each of them. Since it is not just about one possibility but a range of (interrelated) possibilities, Wheeler uses the term involvement-networks: 'the hammer is involved in an act of hammering; that hammering is involved in making something fast; and that making something fast is involved in protecting the human against bad weather' [17, p. 145]. Now, there are all kinds of involvement-networks to which there is some profound unity. Wheeler understands the unity of all involvement-networks as an 'involvement whole', 'a global structure of which involvement-networks (contexts of activity) are local substructures' [17, p. 147]. So, engagement with the world consists, at a fundamental level, of an involvement whole, and possibilities are the fibers forming the fabric of this 'whole'.

Another way of putting some of this is that we have a profoundly action-oriented attitude towards our environment [17]: the environment is perceived from the perspective of potential ranges of actions. ${ }^{4}$ As Maurice Merleau-Ponty says, "[c]onsciousness is in the first place not a matter of "I think that" but of "I can", [22, p. 159].

The second aspect of possibilities is that they eventually relate to the person himself. This was highlighted in the above example of the human agent engaged in building a house for his own shelter. Possibilities are not free floating things that 'may happen' in the future, but they refer either directly or indirectly to the agent

\footnotetext{
${ }^{4}$ Some link Heidegger's theory of possibilities to Gibson's theory of affordances [20], as directly perceived possibilities [21]. Affordances, as a technical term, refers to the possibilities offered by the environment to an animal.
} 
himself. The fact that the involvement-networks in the end refer to the human agent himself makes Wheeler consider them to be 'egocentric'. The formal structure of the whole of these involvement networks, which refers to the agent himself, is the 'worldhood', 'a formal pattern of organization' [17, p. 147]. ${ }^{6}$ It is in these terms that Heidegger describes the nature of human agency, which is characterized by an openness (disclosedness, Erschlossenheit) to the world. Frederik Svenaeus understands the openness of the human being as a striving for meaning: 'This openness is a form of hospitality toward the world - a constant striving to find a place for new phenomena in the meaning pattern, in order to make sense of them' [23, p. 162].

Mood, possibilities, and online engagement

The fact that perceiving possibilities is fundamental to human existence does not entail that it cannot be affected or changed. Heidegger emphasizes that this possibility-recognizing character of our existence is always taking place in some mood [18]. Mood is something which, like the possibility-character of our being, is always there. We may be happy, sad, or even depressed, but there is always some mood in which we encounter the world. And our mood is profoundly related to the actual possibilities we perceive. Heidegger's analysis of the concept of anxiety emphasizes the central role of mood and emotions in our perception of the world and the possibilities it provides [18, pp. 319-335]. In his conception of anxiety, there are no longer significant possibilities left; everything appears to be without (concrete) meaning.

In other words, our moods and emotions are never-to-be-ignored phenomena in the way we disclose the world and the possibilities and options for ourselves. The role of mood and emotions in our engagement with the world (including other human beings) has been emphasized in the work of Matthew Ratcliffe, drawing not only on Heidegger but also on the work of Edmund Husserl and Merleau-Ponty. Ratcliffe says, 'Emotions, and more specifically moods, are philosophically central for Heidegger. They are not merely "subjective" or "psychic" phenomena but an irreducible pre-theoretical background, relative to which the world and the manner in which we are situated within it is disclosed or rendered intelligible' [24, p. 287]. And the way in which the world is intelligible to us is primarily in terms of actual perceived possibilities. Based partly on neuroscientific research, but primarily drawing on a phenomenological account, Ratcliffe states, 'Emotions are neither constituents of explicit intentionalities nor wholly distinct from intentional states. They are a background that serves to structure explicit intentionalities and determine the possible scope of intentional acts and objects, the way in which the world is disclosed' [24, p. 302]. The nature of the engagement with the world takes place through a certain emotional state, which is fundamentally relevant to the

\footnotetext{
5 Within the context of the ontological project of Being and Time, it is important that the possibilities also involve understanding of Dasein's own being or existence [18].

6 The possibilities are not always self-evident. It might very well be that we encounter things for which it is not clear what sort of possibilities they entail (related concepts in Heidegger [18] are Vorhandenheit and Unzuhandenheit). It might take time to find out the things an object enables us to do. However, the usual way in which we relate to the world is by perceiving possibilities.
} 
possibilities that are perceived. It now becomes evident what the analysis of our relationship of engagement with the world and its tools could mean with respect to depression: any profound disturbance of a person's mood could have a serious impact on the way the world and possibilities are perceived.

Ratcliffe quotes various people suffering from mental disorder who express their changed perception and appreciation of the world. An interesting example with respect to depression is his citation of William James's quote of a melancholic patient: " "I see, I hear!" such [melancholic] patients say, "but the objects do not reach me, it is as if there were a wall between me and the outer world!"' [16, p. 229] Such accounts can be understood, of course, in terms of derealization, but it would be interesting to approach them from the perspective of my analysis so far. For such an experience might also be understood as resulting from the fact that the possibilities for action normally provided by engagement with the objects (and people) in the world have somehow drained away. So, the objects are there, but the perception of these objects as disclosing fields of possibilities has changed. If these practical possibilities have in fact drained away, then people might indeed feel, as William James says, that they are 'sheathed in india-rubber; nothing penetrates to the quick or draws blood, as it were' [25, p. 298].

While Ratcliffe emphasizes emotion or mood in the way people perceive possibilities, Wheeler enters the debate from a different angle- the philosophy of artificial intelligence (AI) - emphasizing the fact that one's engagement with the world is an ongoing adaptive process with continuous and new action oriented perception [17]. ${ }^{7}$ He considers this engaged attitude toward the world to be a form of 'online' intelligence: 'A creature displays online intelligence just when it produces a suite of fluid and flexible real-time adaptive responses to incoming sensory stimuli' $\left[17\right.$, p. 12]. ${ }^{8}$ It is clear that this formulation does not only apply to robots and cyborgs; it, rather, shows a basic view of how both robots and organisms (humans included) relate to their environment. This online interaction is especially relevant in a world that is in constant flux-like the world we live in. In order to move forward either as a human being or as a robot, it is necessary to be able to continuously perceive new possibilities, as opposed to working with a fixed cognitive map of the world. Wheeler explains that approaching the interaction of creatures with the environment from this online perspective has been helpful to artificial intelligence. While traditionally, robots were indeed equipped with some sort of fixed map enabling them to engage the world, recent research proves the utility of an online interactive approach to AI. It is important to note that Wheeler is not so much interested in distinguishing online and offline intelligence as he is in emphasizing the importance of online intelligence and interaction, which has often been ignored in AI. In my interpretation of Wheeler's account, I emphasize (see the

\footnotetext{
7 Both Ratcliffe and Wheeler emphasize the role of the body. The centrality of the body is directly related to Merleau-Ponty (see, e.g., [22, pp. 159ff.]). Meanwhile, the body is absent in Heidegger [18]. A difference between Ratcliffe and Wheeler is that while emotions are central to Ratcliffe's account, they are not to Wheeler's.

${ }^{8}$ Wheeler is well aware of the fact that some of his interpretations might be at odds with some Heidegger scholars working in a continental tradition, and he writes, 'I apologize in advance to any Heidegger scholars out there...' [17, p. 20].
} 
following sections) that even in deliberation about treatment options, which might seem to be a rather detached-offline-activity, people have to rely on continuous online perception of new possibilities or environmental cues.

Summarizing this section, human beings are characterized by an online, actionoriented, mood-based perception of possibilities. How does this phenomenological theory apply to depression and informed consent?

\section{Competent decision-making about treatment options}

People make numerous decisions every day, selecting from a manifold of possibilities. We weigh the options and eventually (sometimes very quickly, sometimes after weeks or months) make choices. Decisions about medical treatment options are among the most important decisions we can be faced with. Treatment options are in fact treatment possibilities. I propose that these treatment options be understood as possibilities in the sense just explained: possibilities as disclosing fields or ranges of other possibilities directly relevant to the individual patient.

I now turn to the general scheme for evaluating competence as provided by Paul Appelbaum [4] to find out to what extent 'perceiving possibilities' is relevant to this conceptual framework of competence. As mentioned before, the four domains of human functioning evaluated are:

(1) The ability to communicate a choice,

(2) The ability to understand the information,

(3) The ability to appreciate the situation and its consequences,

(4) The ability to reason about the treatment options.

Two of these domains (items 3 and 4) directly relate to the concept of possibilities. The ability to appreciate the consequences of the situation (item 3 ) entails an appreciation of the possible scenarios that may develop starting at the point where the patient finds herself right now. It is crucial that the patient not just understands the consequences in general or medical terms but that her understanding at this point involves an appreciation of the consequences-possibilities-for herself. These consequences, given the previous analysis, then, could be understood as the range or field of possibilities the current situation entails for the patient herself. Ratcliffe's phenomenological account shows that severely depressed patients may be able to cognitively grasp what consequences might obtain in general or medical terms, but the appreciation thus understood might be significantly influenced by the changed mood.

With respect to item 4 , the ability to appreciate possibilities, the same applies. The consequences of the (various) treatment options as fields of possibilities being disclosed might even be a greater challenge to the severely depressed patient. The patient may well be able to reiterate the doctor's information in terms of risks and recovery rates, etcetera, but the patient may be unable to envisage herself playing in the garden with her grandchildren again, and she may be unable to envisage the joy this may provide to the children, herself, and her husband. Although the treatment options themselves may be understood, appreciating the range of possibilities 
behind these options, which in fact are the ones that basically qualify these options, may be the real challenge for the severely depressed patient. Of course, such appreciation might be more subtle than other changes due to mental disorder, like completely forgetting the procedure proposed by a treating physician in cases of dementia. Still, at least because of the importance of such decisions, consideration of this kind of subtlety is, of course, called for.

Furthermore, it is important to acknowledge that the options presented to a patient are usually not ordinary options; they are rather out of the ordinary. Often, patients, confronted with decisions about treatment, will find themselves in not only a difficult but also a new situation. In line with Wheeler's account, these are exactly the situations in which an 'online' interaction with the environment is essential. In such situations, people cannot just rely on established, fixed cognitive/behavioral patterns, but will have to adapt to new, unforeseen circumstances and their consequences. In fact, recognizing this aspect of decision-making about treatment options reveals one of the weaknesses in Rudnick's proposal [8], which was mentioned in the introduction. In his view, in such new and often unforeseen circumstances, people will make decisions in line with the decisions they made earlier in their lives. If their decision is not consistent with their earlier decisions, there is reason to treat depressed patients as incompetent. Yet, I think it is fair to state that new situations may very well yield new decisions and behavioral responses. People should be free to choose new responses to the challenges they face. As Appelbaum puts it with respect to competence, 'Consistency with past behavior is a difficult determination, especially for unprecedented decisions (e.g., amputation); moreover, a consistency standard [for competence] risks denying patients the right to choose differently today than they have in the past' [26]. So, to summarize, I argue that decisions should result from online engagement with the current situation rather than being in line with previous decisions.

\section{Implications}

Support for an emphasis on emotions

The phenomenological exploration so far clearly provides support for the emphasis on the role of emotions in competent decision-making [7]. In general, it is recognized that factors other than mere 'cognitive' skills contribute to decisionmaking; as Franklin Miller and Donald Rosenstein point out, 'the contributions of mood, motivation and other mental processes on risk assessment and decisionmaking are also pertinent' [27, p. 285]. The further claim, made by Charland, is that emotions are not (sufficiently) represented in the MacCAT-T. The analysis I followed in the previous two sections does not provide grounds for determining whether the MacCAT in practice provides sufficient room for emotions. But it shows that the effects of emotions, namely, on possibilities perceived, may well be covered by the Appelbaum approach and the MacCAT. 
In fact, the real issue brought forward in the present analysis is not so much about emotions themselves but about the nature of people's engagement with the world and the profound relationship between this engagement - understood as perceiving possibilities - and mood. It shows that in evaluating how a patient deals with the various decisional or behavioral responses to the treatment options, one has to keep in mind that adaptive behavior (competent decision-making can be considered to be an important, perhaps core, aspect of such behavior) requires the following three things. Firstly, it needs an appreciation not just of possibilities but of fields or networks of possibilities. Secondly, an appreciation with respect to the person himself, in sum, with respect to the whole of this person's involvement network, is needed. And, thirdly, it needs an online engagement and interaction (not fixed cognitive or behavioral schemes). The severely depressed patient may understand the necessity of an operation in order to live, but the problem is that the depressed patient might be unable to envisage the fields of possibilities open to her should she be operated upon. To be sure, she might perceive some of them, but the mental condition might well affect this perception to an extent that it decisively influences the eventual decision. Such a 'decisive' influence could, indeed, on closer examination, imply that the patient should not be considered competent. In other words, in such cases, a depressed patient's autonomous decision-making has been compromised. In sum, the phenomenological perspective emphasizes that mood and emotions are fundamental to appreciating the world and the options open to us. Therefore, severe mood disturbances may well lead to severe disturbances in the appreciation of options, and consequently, may compromise decision-making to an extent that the patient can no longer be considered competent to make the choice at hand.

Decision-making capacity is always evaluated with respect to a specific treatment choice [3]. So, while a patient might be able to make a competent decision about a specific set of options, she might not be competent to make other kinds of decisions. Therefore, it is always important to find out whether the patient in her particular situation is able to perceive the possibilities relevant to the choice to be made.

As indicated, it is in principle possible to integrate an assessment of these three elements (range, self-relatedness, and online engagement/flexibility) into a 'MacCAT-approach' to competence. Yet, there is also a role for specific attention, focus, and alertness on the part of the assessor when evaluating a (severely) depressed patient. In other words, the analysis so far does not result in new criteria for competence, but calls for a focus or shift in understanding and application of these criteria, at least when evaluating (severely) depressed patients. ${ }^{9}$ Indeed, the suggested approach is compatible with the MacCAT-T approach, just as long as its components are not interpreted beforehand as merely covering rational understanding in detached or medical terms of what will happen when a certain treatment option is chosen. For instance, understanding that 'if the surgery is postponed, I will

\footnotetext{
9 Recently, Jodi Halpern argued for the relevance of mood and emotions with respect to decision-making capacity, introducing the concept of 'concretized emotion-belief complexes' [28]. It is interesting that despite coming from a different philosophical background and moving along different lines of thought, she still arrives at a comparable conclusion-that the specific relevance of emotions and emotional disturbances in assessments of competence should be recognized.
} 
lose my leg, and I will not be able to walk' can never be a sufficient answer to the relevant question, according to the phenomenological account developed in this article. A patient's understanding of options should always be assessed with respect to the patient's particular situation, hopes, desires, and fears. Is the patient capable of grasping what a particular choice will mean for the way her life could unfold? Of course, nobody can be certain about the future, but the phenomenological account implies that, nevertheless, we understand our world continuously in terms of options, i.e., personalized possibilities - the things that I can do in interaction with the environment (importantly, including loved ones). Our ongoing, online appreciation of options is not a prediction about the future but the mental process that enables us to shape our future.

\section{Assessing and supporting patients' appreciation of possibilities}

As has become clear, emotions do not merely provide some color to our existence. Instead, they are central to our appreciation of the world. On a practical level, in the case of evaluating a depressed patient's competence, this could mean asking her to exactly specify the implications and opportunities the various treatment options would entail for her in the future. Going home after an operation may sound to a depressed person as a full stop, as the endpoint, while for others, going home after an operation is a new beginning. This could be a way to assess the possibilities the patient is able to appreciate and contemplate in the decision-making process. Such possibilities are not merely fantasy. In fact, the phenomenological approach suggests that our reality is built on the concrete possibilities we envisage. The moment of winning 10 million Euros is great because of the concrete possibilities it opens up.

This analysis highlights the relevance of an approach to competence that is at least disorder-sensitive in the sense that various mental disorders might bring their own specific challenges to decision-making. Interestingly, Jacinta Tan et al. studied competence in a group of patients diagnosed with anorexia nervosa [29]. They found that these patients were considered competent by the MacCAT-T. However, on reflection, they concluded that these patients were not competent to make treatment decisions because of a disease-related change concerning their values. In parallel with Tan et al., who employed empirical ethics research to show that specific attention for values is called for in anorexia patients, I arrive, based on phenomenological considerations, at the suggestion that the perception of fields of possibilities of depressed patients deserves close attention. Depressed patients, just like anorexia patients, may still possess many of the mental capacities needed for competent decision-making, but subtle, disease-related changes might decisively influence their decision-making. In fact, the outcome of the analysis so far is that even if formal aspects of decision-making are intact in depressed patients, the material with which the decision is being reached (the nature of the fields of options which are perceived) may be changed, or more precisely, be not of the nature that would be required for competent decision-making by this person in this particular situation.

Yet, there might also be another element to be derived from the analysis so far. Wheeler emphasizes that cognitive functioning is in continuous, online interaction 
with the environment. This view-which, as stated already, led to positive results when applied to robotics-could also be relevant to decision-making about treatment options. The online interaction means that people are permanently open to environmental cues which enable them to adjust their planning, decision-making, and behavior. In other words, provided with relevant cues, depressed patients may be able to adjust their decision-making process. Pictures of children or, rather, the actual presence of loved ones can perhaps provide the sort of cues that patients need to better perceive possible consequences for themselves. Online perception of relevant cues is the basis for any adaptation. People who have to decide about their treatment while they stay in hospital may be deprived of many of their normal environmental cues. Accommodating patients' ongoing perception of (new) cues might help them engage the world and confront the actual treatment decisions that have to be made. This is also in line with Josephine Wong et al. who support a 'functional approach,' conceiving of competence from the perspective of an 'interaction between the individual's relevant abilities and the demands of the particular decision-making task, implying that [decision-making] capacity may be maximized by assisting the person to develop his or her relevant abilities and/or by simplifying the task' [30, p. 304]. Meanwhile, one has to note that online responsiveness of severely depressed patients may be strongly diminished. Still, Wheeler's 'online' account suggests that efforts in this direction by care givers could have a substantial effect. Such interventions might be considered related to supportive environmental measures in people suffering from delirium [31]. Nonpharmacological interventions that continuously provide cues about place, time, and, e.g., the name of the nurse can help patients to remain in contact with reality and can significantly improve their condition. ${ }^{10}$

The analysis so far has been conceptual in nature. Several strands of phenomenology clearly indicate the relevance of looking in a specific way at the challenges severely depressed patients may face when it comes to competent decision-making. Yet, the implications mentioned in this section, regarding both the actual assessments and methods for supporting the decision-making process are, in my view, open to empirical research. In the terminology used by Shaun Gallagher and Jesper Sørensen, such research requires 'front-loading phenomenological insights into experimental design' [32]. This comes down to using phenomenological insights in order to support empirical research - in this case, clinical research on competence.

Since the structure of dealing with our world, as discussed earlier, is a basic feature of human agency, it is reasonable to infer that other mental conditions may also profoundly affect this engagement and, therefore, the perception of possibilities. Yet, severe problems or challenges faced by patients suffering from some of these conditions (e.g., dementia) are likely to become evident-even without emphasizing the formal possibility-perceiving structure of people's engagement with the world. In depression, even as many capacities remain intact, the perception

\footnotetext{
${ }^{10}$ The article is about depression. Yet, it might be helpful to look at manic episodes as well. During such a period of time, patients may perceive all kinds of possibilities, envisage themselves in all kinds of (positive) situations, and anticipate a multitude of outcomes. In other words, assessments of competence in manic patients might also benefit from a focus on the perception of possibilities.
} 
of possibilities as understood in this analysis may have changed, which calls for a specific focus when assessing competence in these patients.

\section{Conclusion}

In this article, I applied a phenomenological approach to the clinical question of the specific challenges depressed patients may face when deciding about treatment options. This approach yielded the following considerations. First, as human beings, our understanding of the world takes the form of an online perception of possibilities. In fact, this perception concerns ranges or networks of possibilities rather than individual possibilities, and these networks of possibilities relate to us and to our hopes, fears, etcetera. Second, the way we disclose these possibilities is intimately related to our emotions or moods. These emotions are not a complementary sauce to our cognitive endeavors, but profoundly shape all our encounters with the world. Third, affective disorders like depression, therefore, may significantly affect our understanding of the world, e.g., the future possibilities we perceive and how we appreciate them. Fourth, the analysis, borrowing from Wheeler's recent work on artificial intelligence, suggests the importance of continuous cues for our being in 'online' engagement with our surroundings. In sum, these considerations support an emphasis on emotions as related to (in)competence as well as the idea that different mental disorders may result in specific challenges for patients as far as deciding about treatment options is concerned. From a practical perspective, in actual assessments of competence in severely depressed patients, the future possibilities these patients perceive should be explored in some detail. In addition, providing environmental cues may be one way of enhancing the decision-making capacities of these patients. These practical implications are open to empirical research.

Acknowledgments This work was supported by The Netherlands Organisation for Scientific Research, Grant 275-20-016. I thank Leon de Bruin, Gerrit Glas, Josephine Lenssen, Derek Strijbos, and Sander Voerman for their helpful suggestions.

Open Access This article is distributed under the terms of the Creative Commons Attribution Noncommercial License which permits any noncommercial use, distribution, and reproduction in any medium, provided the original author(s) and source are credited.

\section{References}

1. Paterick, T.J., G.V. Carson, M.C. Allen, and T.E. Paterick. 2008. Medical informed consent: General considerations for physicians. Mayo Clinic Proceedings 83(3): 313-319.

2. Nicholson, T.R., W. Cutter, and M. Hotopf. 2008. Assessing mental capacity: The mental capacity act. British Medical Journal 336(7639): 322-325.

3. Beauchamp, T.L., and J.F. Childress. 2009. Principles of biomedical ethics. 6th ed. New York: Oxford University Press.

4. Appelbaum, P.S. 2007. Clinical practice: Assessment of patients' competence to consent to treatment. New England Journal of Medicine 357(18): 1834-1840. 
5. Grisso, T., P.S. Appelbaum, and C. Hill-Fotouhi. 1997. The MacCAT-T: A clinical tool to assess patients' capacities to make treatment decisions. Psychiatric Services 48(11): 1415-1419.

6. Welie, S.P.K. 2008. Criteria for assessment of patient competence: A conceptual analysis from the legal, psychological and ethical perspectives. Davenport, IA: Fidlar Doubleday Inc.

7. Charland, L.C. 1998. Appreciation and emotion: Theoretical reflections on the MacArthur treatment competence study. Kennedy Institute of Ethics Journal 8(4): 359-376.

8. Rudnick, A. 2002. Depression and competence to refuse psychiatric treatment. Journal of Medical Ethics 28(3): 151-155.

9. Elliott, C. 1997. Caring about risks: Are severely depressed patients competent to consent to research? Archives of General Psychiatry 54(2): 113-116.

10. Charland, L. 2008. Decision-making capacity. Stanford encyclopedia of philosophy. http://plato. stanford.edu/entries/decision-capacity. Accessed Aug.16, 2010.

11. Breden, T.M., and J. Vollmann. 2004. The cognitive based approach of capacity assessment in psychiatry: A philosophical critique of the MacCAT-T. Health Care Analysis 12(4): 273-283.

12. Gill, C.J. 2004. Depression in the context of disability and the 'Right to die'. Theoretical Medicine and Bioethics 25(3): 171-198.

13. Vollmann, J., A. Bauer, H. Danker-Hopfe, and H. Helmchen. 2003. Competence of mentally ill patients: A comparative empirical study. Psychological Medicine 33(8): 1463-1471.

14. Young, E.W., J.C. Corby, and R. Johnson. 1993. Does depression invalidate competence? Consultants' ethical, psychiatric, and legal considerations. Cambridge Quarterly of Healthcare Ethics 2(4): $505-515$.

15. Owen, G.S., A.S. David, G. Richardson, G. Szmukler, P. Hayward, and M. Hotopf. 2009. Mental capacity, diagnosis and insight in psychiatric in-patients: A cross-sectional study. Psychological Medicine 39(8): 1389-1398.

16. Ratcliffe, M. 2009. Understanding existential changes in psychiatric illness: The indispensability of phenomenology. In Psychiatry as cognitive neuroscience: Philosophical perspectives, ed. M.B. Broome, and L. Bortolotti, 223-244. Oxford: Oxford University Press.

17. Wheeler, M. 2005. Reconstructing the cognitive world: The next step. Cambridge, MA: MIT Press.

18. Heidegger, M. 2002. Being and time. Malden: Blackwell.

19. Svenaeus, F. 2010. What is an organ? Heidegger and the phenomenology of organ transplantation. Theoretical Medicine and Bioethics 31(3): 179-196.

20. Gibson, J.J. 1986. The ecological approach to visual perception. Hillsdale, NJ.: Lawrence Erlbaum Associates.

21. Chemero, A. 2003. An outline of a theory of affordances. Ecological Psychology 15(2): 181-195.

22. Merleau-Ponty, M. 2005. Phenomenology of perception. Abingdon: Routledge.

23. Svenaeus, F. 2007. Do antidepressants affect the self? A phenomenological approach. Medicine, Health Care and Philosophy 10(2): 153-166.

24. Ratcliffe, M. 2002. Heidegger's attunement and the neuropsychology of emotion. Phenomenology and the Cognitive Sciences 1(3): 287-312.

25. James, W. 1890. The principles of psychology. Vol. 2. New York: Holt.

26. Appelbaum, P.S. 2008. Response on spike's comment: Patients' competence to consent to treatment. New England Journal of Medicine 358(6): 644.

27. Miller, F.G., and D.F. Rosenstein. 2009. Psychiatric research. In Psychiatric ethics, 4th ed, ed. S. Bloch, and S.A. Green. Oxford: Oxford University Press.

28. Halpern, J. 2010. When concretized emotion-belief complexes derail decision-making capacity. Bioethics. doi:10.1111/j.1467-8519.2010.01817.x.

29. Tan, J.O.A., P.T. Hope, D.A. Stewart, and P.R. Fitzpatrick. 2006. Competence to make treatment decisions in anorexia nervosa: Thinking processes and values. Philosophy, Psychiatry \& Psychology 13(4): 267-282.

30. Wong, J.G., C.H. Clare, A.J. Holland, P.C. Watson, and M. Gunn. 2000. The capacity of people with a 'mental disability' to make a health care decision. Psychological Medicine 30(2): 295-306.

31. Inouye, S.K., S.T. Bogardus Jr., C.S. Williams, L. Leo-Summers, and J.V. Agostini. 2003. The role of adherence on the effectiveness of nonpharmacologic interventions: Evidence from the delirium prevention trial. Archives of Internal Medicine 163(8): 958-964.

32. Gallagher, S., and J.B. Sorensen. 2006. Experimenting with phenomenology. Consciousness and Cognition 15: 119-134. 